\title{
DESEMPENHO EM JUIZADOS ESPECIAIS NO BRASIL: uma análise do período 2009-2016
}

\author{
Jeovan Assis Silva' \\ Guilherme Viana Ferreira ${ }^{2}$ \\ \& Ana Aires Prata ${ }^{3}$
}

\section{Palavras-Chave \\ desempenho judicial/ produtividade/ magistrados/ casos novos/ juizados especiais/carga de trabalho}

\section{SUMÁRIO}

1. Introdução. 2. Desempenho judicial. 2.1. Estudos empíricos sobre desempenho judicial. 3. Os juizados especiais. 4. Método. 4.1. Modelo geral da regressão em painel. 4.2. Modelo de efeitos fixos. 4.3. Modelo de efeitos aleatórios. 4.4. Escolha e especificação do modelo. 5. Resultados e discussão. 6. Conclusão. 7. Referências.

\footnotetext{
'Doutorando no Programa de Pós-Graduação em Administração da Universidade de Brasília (UnB).

${ }^{2}$ Mestrando em Administração. Programa de Pós-Graduação em Administração da Universidade de Brasília.Bacharel em Estatística.

${ }_{3}^{3}$ Mestre em Economia do Setor Público.
}

\section{Resumo}

Este artigo tem como objetivo principal comparar o desempenho dos juizados especiais na Justiça Estadual Brasileira, entre os anos 2009 e 2016, sob a ótica da produção e produtividade. Os juizados especiais são um marco institucional em resposta às pressões oriundas dos problemas de morosidade e da falta de acesso à justiça no Brasil. Críticas recentes, contudo, alertam que esse modelo de justiça já parece sofrer da mesma morosidade que almejou combater. A presente pesquisa busca oferecer contribuições ao estudo do desempenho judicial brasileiro e contextualizar a discussão no contexto dos juizados especiais. Dados secundários oficiais foram analisados por meio da técnica econométrica de regressão em painel, utilizando como variável dependente o Índice de Produtividade dos Magistrados nos Juizados Especiais e, como variáveis independentes, total de servidores da área judiciária, total de magistrados, casos novos e carga de trabalho. Os resultados indicam que o crescimento dos casos novos ao longo dos anos, tem ocasionado o aumento, em menor proporção, da produtividade, enquanto que o aumento do quantitativo de magistrados está relacionado a uma piora no desempenho dos juizados especiais. 


\title{
PERFORMANCE IN SMALL CLAIMS COURTS IN BRAZIL: an analysis of the 2009-2016 period
}

\author{
Jeovan Assis Silva \\ Guilherme Viana Ferreira \\ \& Ana Aires Prata
}

\section{Keywords \\ judicial performance/ productivity/ \\ judges/ new lawsuits/small-claims \\ courts}

\begin{abstract}
The main objective of this article is to compare the performance of small claims courts in the Brazilian State Courts, from 2009 to 2016, from the point of view of production and productivity. Small Claims courts are an institutional framework created in response to pressures arising from problems of judicial slowness and lack of access to justice in Brazil. Recent critics, however, warn that this model of justice already seems to suffer from the same slowness that it sought to combat. The present research seeks to offer contributions to the study of Brazilian judicial performance and to focus the discussion in the context of the small-claims courts. Official secondary data were analyzed using panel econometric regression, using as a dependent variable the Productivity Index of Judges in the Small-Claims Courts. As
\end{abstract}

independent variables, the following ones were used: total number of judicial servants, total number of judges, new lawsuits and workload. The results indicate that the growth of new cases over the years has led to a smaller increase in productivity, while an increase in the number of magistrates is related to a deterioration in the performance of small claims courts. The research complements previous studies with a similar objectives and points to weaknesses in the model of the small claims courts that need to be addressed. 


\section{INTRODUÇÃO}

Apenas recentemente, o Brasil tem buscado aderir a medidas que vêm sendo adotadas em vários países desde o final do século passado, com vistas à melhoria da qualidade dos serviços jurisdicionais, em especial no que tange a políticas de gestão direcionadas para a qualidade e eficiência de resposta ao volume e natureza da litigância (Fabri \& Langbroek, 2000). Contudo, a dinâmica do processo de modernização do judiciário brasileiro tem se mostrado particularmente complexa. Segundo dados do relatório Justiça em Números, do Conselho Nacional de Justiça (CNJ), em 2016 tramitaram, nos 90 tribunais brasileiros, 109,1 milhões de processos (Brasil, 2017). O número é o resultado da soma de 79,7 milhões de processos pendentes (processos que ingressaram antes de 2016) e de 29,4 milhões de casos novos iniciados naquele ano.

Nesse sentido, este trabalho tem como objetivo analisar e comparar variáveis no âmbito dos Juizados Especiais Cíveis (JECs). A pesquisa se mostra relevante na medida em que a criação dos JECs, em 1995, representou uma importante inovação no ordenamento jurídico nacional e incentivou estudos empíricos inéditos (Sadek \& Oliveira, 2012; Cunha, 2008). Contudo, apesar de figurar entre as respostas mais concretas para os problemas de congestionamento e acesso à justiça do Poder Judiciário brasileiro, a evolução desse modelo de jurisdição - marcada por avanços e disfunções - ainda precisa ser mais bem compreendida.

A eficiência do trabalho dos tribunais e juizados remete inevitavelmente à discussão sobre desempenho no setor público. No setor público, o principal objetivo para se mensurar o desempenho é a possibilidade de melhorar a prestação dos serviços oferecidos, além de resultar em práticas mais eficazes de controle, avaliação, execução orçamentária e aprendizagem organizacional (Behn, 2003). Mas cumpre reconhecer que ainda não existe consenso entre o que significa o desempenho na esfera pública, sobretudo porque o Estado e a administração pública contemporânea são, na realidade, compostos de grande diversidade de agências com objetivos altamente heterogêneos, o que dificulta estabelecer padrões comparáveis efetivos.

Pesquisar desempenho de indivíduos e de organizações no Judiciário revela-se ainda particularmente difícil porque não existe consenso a respeito de quais critérios de mensuração devem ser observados (Gomes \& Guimarães, 2013). Apesar da dificuldade de se determinar quais são os principais fatores que compõem o desempenho judicial, sabe-se que o desempenho pode ser visto como uma medida convergente na busca do equilíbrio entre a demanda processual e a capacidade de o Judiciário dar cumprimento ao direito fundamental relativo à razoável duração do processo, incorporado à Constituição Federal pela Emenda Constitucional n. 45, de 2004.

Em sintonia com estudo anterior (Gomes \& Freitas, 2017) focado para o desempenho de varas ( $1^{a}$ instância) da Justiça Federal, o presente artigo focará no desempenho judicial sob o aspecto quantitativo e trabalhará desempenho sob a óptica da produção e produtividade. Parte-se da premissa de que os dados do Relatório Justiça em Números do Conselho Nacional de Justiça podem e merecem ser refinados estatisticamente, uma vez que possuem o potencial de revelar cenários e fenômenos de interesse tanto do meio acadêmico quanto dos profissionais 
encarregados da gestão do sistema de justiça.

\section{DESEMPENHO JUDICIAL}

Transformações da sociedade e do Estado sobretudo, o aumento exponencial dos litígios desde o final dos anos 1970 - colocaram na ordem do dia o debate sobre a produtividade e a qualidade da justiça (Santos, 2007). A pressão quantitativa que recai sobre os tribunais e sobre os juízes colabora para degradar as condições de funcionamento da administração da justiça, colocando em risco a própria qualidade necessária à função jurisdicional.

Mesmo diante de um cenário onde a maioria da população percebe o Poder Judiciário como sistema pouco eficiente, há pouco consenso sobre o que realmente significa eficiência judiciária e, consequentemente, sobre como podemos medir seu desempenho. Na verdade, pode-se dizer que todas as medições relativas à prestação de serviços públicos tendem a ser consideradas de difícil mensuração e avaliação. O âmbito do Poder Judiciário exige a necessidade de se observar suas particularidades administrativas e institucionais, além do cuidado de se considerar outras propriedades da natureza do serviço prestado por este poder (Nogueira, 2010).

Gomes e Guimarães (2013), a partir de revisão de artigos nacionais e internacionais publicados entre 1992 e 2011, identificaram as seguintes dimensões relacionadas ao desempenho judicial: eficiência, celeridade, independência, efetividade, acesso e qualidade. Os autores ressaltam que há um aumento no número de estudos desta temática a partir do ano de 2009 e ressaltam que medir o desempenho no Judiciário envolve deparar-se com a inexistência de consenso a respeito de quais critérios devem ser observados. Também reconhecem que o próprio termo carrega diferentes entendimentos que podem ser associados a diferentes dimensões. Assinalam, ainda, que a definição de desempenho judicial aponta para uma enorme variedade de entendimentos, que abordam variáveis objetivas e subjetivas, de diferentes níveis de análise e associadas a diferentes dimensões de desempenho. Essa abrangência acaba dificultando a evolução teórica a respeito do tema, uma vez que os resultados dos estudos pouco se comunicam entre si.

Não é incomum, contudo, em estudos realizados em judiciários de vários países, que fatores como demanda e quantidade de pessoal (especialmente de juízes) se sobressaiam como relevantes para a aferição do desempenho judicial (Gomes \& Freitas, 2017). No caso da demanda, comumente almeja-se compreender de que modo o volume do acervo de uma unidade de justiça influencia na produtividade dos magistrados dessa unidade.

\subsection{Estudos empíricos sobre desempenho judicial}

A revisão de literatura empreendida revelou diversos trabalhos acadêmicos que se propuseram a estudar os determinantes do desempenho judicial, a maioria em contextos nacionais, isto é, analisando variáveis representativas do judiciário de cada país. A maioria dos estudos trata dos países europeus, seguido por brasileiros, multinacionais e apenas um estudo norte americano, quando considerado o período de publicação de 2012 a 2018 e o enfoque na eficiência.

Diversos dos artigos a seguir descritos utilizaram as técnicas estatísticas DEA (Data Envelopment Analysis - Análise Envoltória 
de Dados) e DDF (Directional Distance Function - Função de Distância Direcional) para mensurar a eficiência relativa. Ambas as análises utilizam insumos e produtos de forma a calcular uma fronteira de eficiência, na qual são projetadas as unidades de análise (geralmente os tribunais), permitindo a comparação e identificação de quais insumos devem ser modificados de forma a maximizar a eficiência (Falavigna, Ippoliti, Manello \& Ramello, 2014). Outra parte considerável dos estudos aplicou variadas técnicas de regressão linear, com o intuito de avaliar a contribuição de algumas variáveis independentes no desempenho judicial (variável dependente).

O primeiro estudo, de Dimitrova-grajzl, Grajzl, Sustersic e Zajc (2012), analisou a $1^{\mathrm{a}}$ instância da justiça eslovena, examinando a influência que o pessoal ligado à área judicial e os processos pendentes têm nos processos finalizados. Com atenção aos problemas comuns de endogeneidade e causalidade reversa, os autores utilizaram diversas técnicas distintas de regressão com o intuito de controlar essas violações. Como resultado foi demonstrada a importância de tratar a endogeneidade, além da alta influência que a demanda tem sobre o principal produto judicial: as sentenças.

Cumpre destacar alguns trabalhos no âmbito do judiciário italiano, considerado um dos mais lentos e ineficientes da Europa e que sofreu ampla reforma procedimental em 2009 (Esposito, Lanau \& Pompe, 2014). Falavigna et al. (2014). Considerando o período de 2009 a 2011, enfocaram a diferença entre os métodos DEA e DDF na estimação da eficiência judicial e utilizando técnicas de bootstrap para robustecer os dados, foram incluídos como "entradas" (inputs) número de juízes, casos pendentes e casos novos e como "saída" (output) os casos concluídos. Os achados, em ambos os métodos, apontaram para a superioridade de eficiência da região noroeste da Itália, assim como a identificação de alguns gargalos do processo tributário italiano. Peyrache e Zago (2015), na aplicação da técnica de DDF, apontaram ineficiências no judiciário italiano no período de 2003 a 2008. Como outputs foram utilizadas as informações de casos resolvidos, subdivididos em cível, trabalhista, seguridade social e criminal; e como inputs o número de juízes, pessoal administrativo e número de casos pendentes (cível e criminal). Ao dividirem a eficiência geral em três categorias distintas - tamanho, técnica e realocação - os autores conseguiram indicar, mais especificamente, as ineficiências do setor no período estudado: a falta de boas práticas (técnica) corresponde a 38\% da ineficiência, o tamanho excessivo dos tribunais (entre $22 \%$ e $25 \%$ ) e a alocação aquém do ótimo (entre 30\% e 40\%). Castro e Guccio (2014), utilizando instrumental semelhante ao empregado por Falavigna et al. (2014), avaliaram o judiciário italiano em 2006 aplicando o DEA em dois estágios e aplicação de bootstrap para regularizar as estimadas obtidas. Como inputs foram escolhidas as variáveis de número de juízes, pessoal administrativo e casos pendentes; e como output, casos resolvidos, divididos entre tipo (comum e outros). A fronteira de eficiência apontou apenas 4 tribunais eficientes, e a regressão da $2^{a}$ etapa demonstrou que a eficiência, nessa amostra, está relacionada positivamente à taxa de litigação, e negativamente à duração do processo e ao número de advogados per capita. Guerra e Tagliapietra (2017) relacionaram a rotatividade de juízes italianos com a demora processual. Baseando-se em dados em painel, do período de 2008 a 2012, de cortes de apelação, os 
autores aplicaram modelo de regressão de diferenças em diferenças para concluir que a quanto mais alta a rotatividade, menor o desempenho judicial, tendo como base as métricas de congestionamento e resolução de processos.

No judiciário búlgaro, Dimitrova-grajzl, Grajzl, Slavov e Zajc (2015) exploraram a possível relação entre eficiência judicial e qualidade. Utilizando dados em painel do período de 2005 a 2013 e as técnicas de regressão pooled, regressão em painel com efeitos fixos e regressão com variável instrumental, a variável de casos resolvidos foi explicada pelo número de juízes, casos pendentes e casos recorridos. A utilização da variável de processos recorridos como proxy da qualidade judicial revelou não haver tradeoff nas cortes búlgaras, quando consideramos produção e qualidade. Ainda assim, um ponto comum com outros estudos pode ser destacado: tribunais maiores, com mais resoluções, tendem a ter menor número de apelações; já cortes menores, com também alto número de resoluções, têm também alto número de apelações. Esse fato aponta, mais uma vez, para a correlação entre demanda e produtividade.

Fora do continente europeu, fugindo da variável comumente utilizada de casos resolvidos, Choi, Gulati e Posner (2013) utilizaram variáveis exógenas ao cotidiano da corte para explicar o desempenho judicial norte americano e sua qualidade. Apesar de partirem de uma base bem específica, de ações coletivas, os resultados são interessantes: juízes ativos academicamente, medido pelo número de publicações e citações de seus trabalhos, têm melhor desempenho de acordo com o indicador escolhido pelos pesquisadores, que foi a moção de rejeição. A hipótese sustentada é de que juízes que optam pela moção de rejeição devem embasar de forma impecável sua decisão, para que não seja modificada nas instâncias superiores.

No Brasil, para relacionar a eficiência do judiciário estadual brasileiro com os investimentos em TI, Andrade e Joia (2012) utilizaram o método de estudo de caso para chegar à conclusão de que há correlação positiva entre o montante investido em Tecnologia da Informação e a eficiência do tribunal, medida pela Taxa de Congestionamento. Os autores relataram também que, um maior congestionamento está ligado à ineficiência operacional e a maiores custos de operação, vinculando os conceitos econômicos de eficiência.

Ainda nos Tribunais de Justiça (TJ) brasileiros, mas de forma mais geral, Nogueira, Oliveira, Vasconcelos e Oliveira (2012) buscaram mensurar a eficiência dos TJs utilizando a técnica DEA. Como inputs foram escoIhidas as variáveis de despesa total, número de pessoal auxiliar, gastos com informática, casos novos, total de magistrados e recursos internos; como produto (outputs) custas e recolhimentos diversos e sentenças. Analisando os anos de 2007 e 2008, verificou-se aumento no número de tribunais tecnicamente eficientes de um ano a outro, e fez-se o benchmarking entre esses tribunais e o tribunal do Ceará, de forma a apontar opções de melhoria. Dentre essas opções, as duas mais efetivas seriam a diminuição do número de magistrados do TJCE, e o aumento no quantitativo de julgamentos, de forma a liquidar os casos pendentes; ambas as ações de difícil implementação.

Somando-se às iniciativas brasileiras de aplicação de DEA nos dados do relatório "Justiça em Números", Yeung (2014) ana- 
lisou os Tribunais de Justiça Estaduais, no período de 2006 a 2010, de forma a explorar a fronteira de eficiência e apontar possíveis boas práticas. Os inputs (pessoal da área fim judiciária e número de juízes na $1^{a}$ e $2^{a}$ instâncias) e outputs (casos concluídos na $1^{a}$ e $2^{a}$ instâncias) seguem o padrão dos trabalhos com esse método. Os resultados indicaram que a maioria dos tribunais em todos os anos analisados, estavam aquém da eficiência máxima - o TJ do Rio Grande do Sul foi o único plenamente eficiente em todos os anos considerados, fato que merece aprofundamento, de forma a verificar as especificidades positivas desse tribunal e compartilha-las entre os demais.

Com foco no efeito da força de trabalho no desempenho judicial brasileiro, Gomes, Guimarães e Akutsu (2016) utilizaram regressão em painel, no período de 2003 a 2012, dos 27 Tribunais de Justiça Estaduais. A relação entre produtividade, medida pelo número de sentenças, e demanda, medida pelo número de processos pendentes, é direta, corroborando com diversos estudos anteriores. A utilização das variáveis de número de juízes e de assistentes judiciais mostrou que apenas o quantitativo de assistentes modera negativamente a relação entre produtividade e demanda, ou seja, o aumento ao longo dos anos do número de assistentes judiciais teria efeito negativo na produtividade.

Todos os estudos acima preocuparam-se com os determinantes da eficiência judicial em nível nacional, ou seja, como as particularidades de cada local afetam a eficiência judicial. Voigt e El-Bialy (2016) utilizaram dados multinacionais coletados pelo CEPEJ (European Comission for the Efficiency of Justice) entre os anos de 2004 e 2010. As estimativas foram calculadas utilizando regressão robusta em painel e diversas conclusões interessantes emergiram sobre a taxa de resolução (relação entre processos concluídos e ingressantes): não estão correlacionadas ao orçamento per capita, estão relacionadas negativamente com o orçamento total; países da tradição legal francesa têm taxas de resolução ligeiramente menores; a presença de conselho judicial (como o CNJ no Brasil) afeta negativamente a resolução; treinamento obrigatório aumenta as taxas de resolução.

Também utilizando dados do CEPEJ, Deyneli (2012) estudou a relação entre a eficiência judicial e os salários dos juízes nos países europeus, utilizando a técnica de DEA em dois estágios. No primeiro estágio foram utilizadas as variáveis número de juízes e número de servidores da área fim como inputs e sentenças como output. No segundo estágio, os resultados da fronteira de eficiência foram utilizados como variável dependente de uma regressão Tobit e o número de tribunais, os salários e educação dos juízes figuraram como variáveis independentes. Os resultados mostraram que há uma relação positiva e estatisticamente significante entre as variáveis de interesse, isto é, o aumento do salário dos juízes está, nesse estudo, relacionado ao aumento da eficiência judicial nas cortes europeias. Ainda assim, o autor ressalta que essa certamente não seria a solução ideal para o problema da ineficiência judicial.

A compreensão do desempenho judicial requer o entendimento baseado em pesquisas empíricas não apenas sobre a eficiência dos tribunais, mas também do comportamento e sistema de incentivos dos atores que participam. O estudo dessa área tem crescido ao longo dos anos, mas ainda carece de aprofundamento, especialmente no Brasil, devido à falta de disponibilidade de 
dados desagregados.

Seguindo as conclusões de Pekkanen e Niemi (2013) podemos perceber, após a análise dos estudos referenciados, que há lacunas empíricas no que tange ao entendimento das relações causais e ao porquê da utilização de diversas medidas. Quase todos os estudos utilizam como base as mesmas variáveis: número de juízes e de sentenças. A diferença fica por conta da técnica estatística escolhida. A falta de aprofundamento nos dados fica muito clara, resta saber se isso ocorre por conta de indisponibilidade de dados desagregados, ou do foco que ainda está na generalidade da abordagem, o que já vem sendo abordado há alguns anos na literatura sobre desempenho judicial.

Já os estudos que calculam a fronteira de eficiência (DEA ou DDF) fornecem informações complementares, no sentido de apontar quais indicadores devem ser melhorados, de forma a aumentar a produtividade das unidades analisadas. O trabalho de Yeung (2014), por exemplo, fornece um guia de ações a serem tomadas em cada tribunal, com o objetivo de assemelhar sua eficiência à do TJ do Rio Grande do Sul, que no período de 2006 a 2010 foi o tribunal de justiça mais eficiente, quando considerada a relação pessoal judiciário (servidores e juízes) e número de sentenças. Nesse sentido, são feitas ressalvas nos limites a serem observados para a busca da maior produtividade (Falavigna et al., 2014), pois há um custo social envolvido.

Pode-se concluir ainda, que os estudos se preocupam apenas com o judiciário e não com o sistema de justiça. Não foi encontrado na revisão de literatura empreendida, nenhum artigo que abordasse dados além do judiciário. Além disso, identifica-se uma certa desatenção por grande parte dos autores, em relação a proble- mas de endogeneidade e causalidade reversa, algo muito comum em estudos empíricos sociais (Voigt, 2016) e facilmente contornável com diversos métodos estatísticos existentes.

\section{OS JUIZADOS ESPECIAIS}

Inspirados na experiência norte-americana das chamadas Small Claim Courts (tribunais de pequenas causas), os Juizados Especiais no Brasil são marcados por uma tensão entre aumentar e facilitar o acesso dos cidadãos à justiça por meios institucionais alternativos ao poder judiciário e simplesmente descongestionar a justiça estatal, ao ampliar o espectro da sua atuação pela simplificação de procedimentos (Mello \& Meirelles, 2010). Em Portugal, esse modelo de justiça já recebeu críticas por envolver uma justiça padronizada, marcada por processos repetitivos e que estaria mobilizando cada vez mais profissionais, em prejuízo do tempo e da atenção que deveriam ser dedicados a litígios mais complexos, que se eternizam nos tribunais (Santos, 2005).

Apesar de a presente pesquisa enfocar o desempenho dos juizados a partir de uma abordagem quantitativa, a compreensão do pano de fundo institucional que permeia a criação dos juizados especiais e seu funcionamento até os dias de hoje, também contribui para a discussão da performance desse modelo jurisdicional. Vianna et al. (1999), consideram os juizados como peça importante do processo de construção democrática do Brasil pós-1988 e os inserem no quadro mais amplo da popularização da justiça e ampliação do acesso para uma considerável parcela de cidadãos que anteriormente eram mantidos à margem do sistema. Cunha (2008) recorda a ideia de "litigiosidade contida" construída à época de criação dos juizados representava uma demanda social, porém também questiona em que medida o próprio juizado especial terminou criando 
novas demandas, que talvez não emergissem sem esse instituto. Essa autora recorda que a criação dos juizados teve origem em grupos distintos (Poder Executivo, Poder Judiciário, Ministério Público, dentre outros) e envolve uma construção institucional que envolveu diferentes intenções e motivações e implicou diferentes processos de implementação nas unidades da federação. Também no intuito de compreender o funcionamento institucional dos juizados, Chasin (2012) relaciona essa modalidade de jurisdição à tensão entre a motivação de ampliação do acesso à justiça e a finalidade de desafogamento da justiça comum, sendo que esta última começou a prevalecer a partir da década de 1990. No que tange o funcionamento dos juizados na prática, a autora identificou que as audiências de conciliação eram centradas na negociação de valores e não de direitos, bem como elevada assimetria entre as partes litigantes.

Ao prever a criação dos juizados especiais cíveis e criminais na esfera estadual (Art. 98 da CF/1988), a Constituição almejava o fortalecimento institucional de uma Justiça diferenciada, mais simples, barata e célere do que a Justiça Comum e que incorporava novos pro- cedimentos, formas de resolução de conflitos e decisões judiciais (IPEA, 2010). Os juizados especiais sucederam aos juizados de pequenas causas criados em 1984 pela Lei n. 7.244/1984, com a ampliação de sua competência no campo penal e na capacidade de executar suas decisões. Sinteticamente, possuem atribuições para conciliar, julgar e executar causas cíveis de menor complexidade e infrações penais de menor potencial ofensivo mediante os procedimentos orais menos burocratizados, que nas ações cíveis de valor inferior a vinte salários mínimos, dispensam a figura do advogado.

A Tabela 1 (abaixo) traz um panorama de quantidade de magistrados, casos novos, casos pendentes, processos baixados e juízes nos Juizados Especiais das 27 Unidades da Federação (UFs) ao final do ano de 2016. O estoque de processos (casos novos e pendentes) nos juizados alcançou 11.765 .648 processos, o que representa cerca de 10,7\% do total de processos em tramitação no país (em todas as esferas e instâncias do Poder Judiciário). O quantitativo de processos baixados é próximo do número de casos novos, o que aponta para uma estabilidade na cifra de processos pendentes de solução.

Tabela 1 - Detalhamento das variáveis dos Juizados Especiais para o ano de 2016 por UF

\section{Tribunal}

$\mathrm{TJ}$ - Acre

TJ - Alagoas

$\mathrm{TJ}$ - Amazonas

TJ - Amapá

TJ - Bahia

TJ - Ceará

TJ - Distrito Federal

TJ - Espírito Santo

\section{Casos Novos}

15.251

38.028

59.639

30.398

368.667

52.404

131.365

84.730
Casos Pendentes

22.400

54.936

76.098

23.117

908.707

62.797

73.409

196.120
Processos Baixados*

23.199

39.125

54.872

41.761

296.877

50.873

126.126

173.519

\section{Magistrados}

9

19

22

15

75

41

42

68 


$\begin{array}{lllll}\text { TJ - Goiás } & 206.164 & 253.344 & 199.346 & 81 \\ \text { TJ - Maranhão } & 122.933 & 425.891 & 114.219 & 137 \\ \text { TJ - Minas Gerais } & 540.771 & 553.167 & 439.847 & 376 \\ \text { TJ - Mato Grosso do Sul } & 91.581 & 75.398 & 91.078 & 70 \\ \text { TJ - Mato Grosso } & 224.647 & 205.243 & 231.702 & 87 \\ \text { TJ - Pará } & 54.917 & 91.975 & 47.077 & 68 \\ \text { TJ - Paraíba } & 48.609 & 67.978 & 83.163 & 20 \\ \text { TJ - Pernambuco } & 102.905 & 150.546 & 147.510 & 59 \\ \text { TJ - Piauí } & 49.661 & 79.896 & 43.714 & 27 \\ \text { TJ - Paraná } & 374.909 & 399.652 & 306.236 & 223 \\ \text { TJ - Rio de Janeiro } & 840.012 & 903.458 & 1.026 .688 & 82 \\ \text { TJ - Rio Grande do Norte } & 84.215 & 109.322 & 81.565 & 43 \\ \text { TJ - Rondônia } & 56.593 & 66.283 & 40.485 & 12 \\ \text { TJ - Roraima } & 14.840 & 7.741 & 17.287 & 5 \\ \text { TJ - Rio Grande do Sul } & 506.808 & 350.014 & 482.343 & 221 \\ \text { TJ - Santa Catarina } & 177.355 & 323.464 & 294.636 & 215 \\ \text { TJ - Sergipe } & 63.746 & 39.367 & 51.259 & 17 \\ \text { TJ - São Paulo } & 621.962 & 1.223 .934 & 900.071 & 702 \\ \text { TJ - Tocantins } & 30.315 & 27.966 & 25.743 & 16 \\ \text { Total } & \mathbf{4 . 9 9 3 . 4 2 5} & \mathbf{6 . 7 7 2 . 2 2 3} & \mathbf{5 . 4 3 0 . 3 2 1} & \mathbf{2 . 7 5 2} \\ \text { Média } & \mathbf{1 8 4 . 9 4 2} & \mathbf{2 5 0 . 8 2 3} & \mathbf{2 0 1 . 1 2 3} & \mathbf{1 0 2} \\ \text { Desvio-padrão } & \mathbf{2 1 1 . 6 8 8} & \mathbf{3 0 7 . 0 8 3} & \mathbf{2 4 9 . 5 7 6} & \mathbf{1 4 5} \\ \text { Fonte: CNJ - Justiça em Números } & & & & \end{array}$

Nota: *Processos baixados são aqueles sentenciados, remetidos para outra instância competente ou arquivados definitivamente.

A Tabela 1 revela a grande heterogeneidade dos juizados especiais nas 27 UFs. Estudo do IPEA, concluído em 2013, confirmou esse caráter heterogêneo dos juizados especiais, marcados por uma multiplicidade de experiências no processo de implementação em cada Estado da Federação (IPEA, 2013). Primeiramente, cumpre informar que o quantitativo de magistrados se refere aos juízes que lidaram com processos de competência de juizado especial e não aos que estavam exclusivamente dedicados a eles.
Desse modo, a diferença existente entre o quantitativo de magistrados nas UFs é atribuível ao fato de que, frequentemente, um magistrado acumula funções no juizado especial e com o juízo da Justiça Comum (adotando os ritos processuais diferentes para cada situação específica). Em cidades pequenas é comum haver uma única vara judicial encarregada de receber os mais variados tipos de processo. Mesmo no caso do Tribunal de Justiça do Distrito Federal (TDFT), cuja organização judiciária destinou 
varas exclusivas para os juizados, cumpre atentar que, ainda assim, há magistrados que acumulam funções tanto nos juizados quanto em turmas recursais (que recebem os recursos dos juizados).

A Tabela 2 apresenta uma série histórica dos casos novos nos juizados especiais, em comparação com a situação da justiça comum de $1^{\circ}$ grau (Justiça Estadual). Os juizados apresentaram um crescimento, entre 2009 e 2016 , de 3,07\%, enquanto que no $1^{\circ}$ grau houve uma certa estagnação $(0,20 \%)$.

\section{Tabela 2 - Série histórica comparada dos casos novos,}

$1^{\circ}$ Grau e Juizado Especial, 2009 a 2016

\begin{tabular}{|c|c|c|c|c|c|c|c|c|c|}
\hline $\begin{array}{l}\text { Casos } \\
\text { Novos }\end{array}$ & 2009 & 2010 & 2011 & 2012 & 2013 & 2014 & 2015 & 2016 & $\begin{array}{l}\text { Crescimento } \\
2009-2016\end{array}$ \\
\hline 1o Grau & 11.560 .161 & 11.245 .335 & 12.124 .252 & 12.816 .322 & 13.053 .961 & 12.533 .185 & 11.537 .812 & 11.725 .599 & $0,20 \%$ \\
\hline $\begin{array}{l}\text { Juizado } \\
\text { Especial }\end{array}$ & 4.040 .909 & 3.970 .679 & 4.076 .619 & 4.287 .137 & 4.856 .978 & 4.838 .881 & 4.787 .937 & 4.993 .425 & $3,07 \%$ \\
\hline
\end{tabular}

Em relação aos casos pendentes, na comparação entre juizados especiais e $1^{\circ} \mathrm{grau}$ (Tabela 3), observa-se um crescimento nos juizados de 5,08\%, que se revela superior ao verificado na Justiça Comum (3,20\%).

Tabela 3 - Série histórica comparada dos casos pendentes, $1^{\circ}$ Grau e Juizado Especial, 2009 a 2016

\begin{tabular}{|c|c|c|c|c|c|c|c|c|c|}
\hline $\begin{array}{l}\text { Casos } \\
\text { Pendentes }\end{array}$ & 2009 & 2010 & 2011 & 2012 & 2013 & 2014 & 2015 & 2016 & $\begin{array}{l}\text { Crescimento } \\
2009-2016\end{array}$ \\
\hline 1o Grau & 42.932 .153 & 44.381 .716 & 45.853 .645 & 47.116 .772 & 49.973 .310 & 49.419 .705 & 52.803 .751 & 53.509 .826 & $3,20 \%$ \\
\hline $\begin{array}{l}\text { Juizado } \\
\text { Especial }\end{array}$ & 4.787 .521 & 4.036 .541 & 4.487 .347 & 5.054 .825 & 5.687 .052 & 5.520 .005 & 6.678 .402 & 6.772 .223 & $5,08 \%$ \\
\hline
\end{tabular}

\section{Fonte: CNJ - Justiça em Números}

Na série histórica (2009-2016) comparada dos processos baixados (Tabela 4), verifica-se que os juizados apresentam um desempenho melhor na conclusão das causas que lhes são submetidas (crescimento de 2,86\%) em comparação com o $1^{\circ}$ grau (crescimento de apenas $0,55 \%)$. 
Tabela 4 - Série histórica comparada dos processos baixados, $1^{\circ}$ Grau e Juizado Especial, 2009 a 2016

\begin{tabular}{|c|c|c|c|c|c|c|c|c|c|}
\hline $\begin{array}{l}\text { Processos } \\
\text { baixados }\end{array}$ & 2009 & 2010 & 2011 & 2012 & 2013 & 2014 & 2015 & 2016 & $\begin{array}{l}\text { Crescimento } \\
2009-2016\end{array}$ \\
\hline 1o Grau & 11.877 .242 & 10.716 .984 & 11.650 .030 & 12.306 .580 & 11.945 .524 & 12.248 .034 & 11.890 .840 & 12.342 .893 & $0,55 \%$ \\
\hline $\begin{array}{l}\text { Juizado } \\
\text { Especial }\end{array}$ & 4.457 .459 & 4.335 .133 & 4.200 .864 & 4.268 .046 & 4.922 .188 & 4.975 .025 & 5.115 .623 & 5.430 .321 & $2,86 \%$ \\
\hline
\end{tabular}

Fonte: CNJ - Justiça em Números

Pesquisas especificamente voltadas para os juizados especiais cíveis (JECs) têm mostrado que desde sua criação, os litígios envolvem predominantemente relações de consumo de serviços e produtos (Cunha, 2008). Mais particularmente, atenderiam a um constante litígio de massa, com destaque para reclamações de serviços públicos prestados por concessionárias, em prejuízo de decisões mais artesanais (IPEA, 2010). No Brasil, alguns autores postulam que os JECs se tornaram balcões de triagem das causas que devem ou não ser apreciadas pela justiça comum e aquelas que constarão como meras reclamações do pequeno consumidor perante grandes litigantes (Mello \& Meirelles, 2010).
O Relatório Justiça em Números 2017 (ano-base 2016) trouxe informações relativas a detalhamento de assuntos e classes processuais e respectivas quantidades de processos (cadastrados em 2016). Para os juizados especiais, as informações são apresentadas na Tabela 5. Observa-se que, no que tange aos assuntos, há uma certa diversificação, com relativo destaque para temas afetos ao direito do consumidor (responsabilidade do fornecedor). No que tange às classes, 59,26\% dos processos eram de conhecimento e apenas $6,76 \%$ eram criminais (o que condiz com a competência restrita dos juizados para processos dessa natureza).

\section{Tabela 5 - Quantitativo de processos cadastrados*, por assunto e classe nos Juizados Especiais - 2016}

\begin{tabular}{|c|c|c|c|}
\hline Assuntos & Quantidade & Classes & Quantidade \\
\hline $\begin{array}{l}\text { Responsabilidade do } \\
\text { fornecedor/Indenização } \\
\text { por dano moral }\end{array}$ & $1.235 .983(15,15 \%)$ & Processo de Conhecimento & $4.124 .934(59,26 \%)$ \\
\hline Responsabilidade civil & $554.922(6,18 \%)$ & $\begin{array}{l}\text { Processo Criminal } \\
\text { (Procedimentos Investigatórios/ } \\
\text { Termo circunstanciado }\end{array}$ & $470.488(6,76 \%)$ \\
\hline $\begin{array}{l}\text { Obrigações (Títulos de } \\
\text { crédito) }\end{array}$ & $345.148(4,23 \%)$ & $\begin{array}{l}\text { Processo de Execução } \\
\text { (Execução de título extrajudicial) }\end{array}$ & $351.578(5,05 \%)$ \\
\hline Obrigações (Contratos) & $338.750(4,16 \%)$ & \multirow[b]{2}{*}{$\begin{array}{l}\text { Outros procedimentos (Cartas, } \\
\text { procedimento de cumprimento de } \\
\text { sentença e decisão) }\end{array}$} & \multirow[b]{2}{*}{$254.204(3,65 \%)$} \\
\hline $\begin{array}{l}\text { Responsabilidade do } \\
\text { fornecedor/Indenização } \\
\text { por dano material }\end{array}$ & $268.834(3,30 \%)$ & & \\
\hline
\end{tabular}

Fonte: CNJ - Justiça em Números

Nota: * O próprio relatório do $\mathrm{CNJ}$ esclarece que os totais de processo com identificação de classe e/ou assunto não coincidem com o total de casos novos ingressado no ano e, portanto, referem-se tão somente aos processos cadastrados nessas categorias. 


\section{MÉTODO}

Os casos selecionados para esse estudo são os Juizados Especiais que funcionam no âmbito dos 27 Tribunais da Justiça Estadual (TJs). Serão utilizados dados secundários do Relatório Justiça em Números, regulamentado pela Resolução n. 76/2009 do CNJ e publicado anualmente pelo Conselho Nacional de Justiça. O documento, também disponibilizado na internet na forma de planilhas eletrônicas, apresenta informações na forma de variáveis e indicadores estatísticos para as seguintes categorias: receitas, despesas, estrutura, carga de trabalho, taxa de congestionamento, recorribilidade, reforma de decisões, dentre outras.

Os dados analisados referem-se aos 27 tribunais estaduais brasileiros, no período de 2009 a 2016, os quais totalizam 216 observações. O foco do artigo são os Juizados Especiais, então todas as variáveis são específicas a essa esfera da justiça. O recorte temporal partiu de uma análise de disponibilidade e qualidade dos dados. Para analisar esses dados, a técnica econométrica de regressão em painel foi utilizada, pois a base de dados é composta por entidades (no caso os TJs) que foram observadas em repetidos pontos no tempo, caracterizando informações longitudinais (Batalgi, Egger \& Pfaffermayr, 2012). Os softwares estatísticos $R$ versão 3.4 .2 e RStudio versão 1.1 .383 foram utilizados no preparo e tratamento dos dados.

\subsection{Modelo geral da regressão em painel}

O modelo geral da regressão com dados em painel é dado por:

$$
y_{i t}=\beta_{0 i t}+\beta_{1 i t} x_{1 i t}+\cdots+\beta_{n i t} x_{n i t}+e_{i t}
$$

Na notação acima, o subscrito i representa os diferentes indivíduos, que no caso deste trabalho são os Tribunais de Justiça, enquanto que o subscrito $t$ denota o período correspondente, o que, mais uma vez, nesta aplicação, refere-se aos anos de 2009 a 2016. O intercepto está representado pelo $\beta_{0}$, enquanto que os coeficientes são representados pelos $\beta_{k}$ A variável dependente $y_{i t}$ corresponde à variável Índice de Produtividade dos Magistrados, e as variáveis independentes, $x_{k i t}$, correspondem às variáveis Total de Magistrados, Total de Servidores lotados na Área Judiciária, Casos Novos (Conhecimento e Execução) e Carga de Trabalho (Conhecimento e Execução).

Tal modelo teórico, da forma descrita, não possibilita a estimação de seus parâmetros, devido à sua formulação: mais parâmetros desconhecidos do que observações. Dessa forma, é necessária a especificação de suposições baseadas nesse modelo geral; as mais comuns são os Modelos de Efeitos Fixos e Modelos de Efeitos Aleatórios.

\subsection{Modelo de efeitos fixos}

O modelo de efeitos fixos tem como objetivo controlar os efeitos das variáveis omitidas que variam entre indivíduos e mantêm-se constante ao longo do período observado. Dessa forma, a suposição principal é de que o intercepto varia de um indivíduo a outro, mas permanece constante ao longo dos anos, e de que os parâmetros resposta são constantes para todos os indivíduos, independentemente do período. Matematicamente, isso se traduz em:

$$
\begin{gathered}
\beta_{0 i t}=\beta_{0 i}=\alpha_{i} \\
\beta_{1 i t}=\beta_{1} \ldots \beta_{k i t}=\beta_{k}
\end{gathered}
$$


Dessa forma, o modelo de efeitos fixos é:

$$
y_{i t}=\alpha_{i}+\beta_{1} x_{1 i t}+\cdots+\beta_{n} x_{n i t}+e_{i t}
$$

Como os parâmetros resposta não variam entre indivíduos e nem ao longo do tempo, todas as possíveis diferenças serão captadas pelo intercepto, ou seja, $\alpha_{i}$ pode ser interpretado como o efeito que variáveis omitidas têm no modelo. Desse pressuposto temos a seguinte consequência: todas as inferências do modelo só podem ser aplicadas aos indivíduos dos quais há dados disponíveis.

O consenso é de que o modelo de efeitos fixos tem sua melhor utilização Dara dados em painel, quando o intercepto $\alpha_{i}$ é correlacionado com as variáveis explicativas, em qualquer dos períodos utilizados (Hill, Griffiths \& Judge, 1999). Adicionalmente, sua aplicação é desejável quando os dados correspondem a toda população, o que possibilita que as inferências feitas apliquem-se a todos os indivíduos contemplados.

\subsection{Modelo de efeitos aleatórios}

O modelo de regressão com efeitos aleatórios possui as mesmas suposições do modelo de efeitos fixos, porém o tratamento do intercepto é diferente: ao invés de ser um parâmetro fixo, o intercepto é considerado uma variável aleatória, ou seja, é tratado como se fosse uma amostra aleatória de um conjunto maior de observações. Matematicamente, temos:

$$
\beta_{0 i t}=\bar{\beta}_{0}+\alpha_{i}
$$

O modelo pode, então, ser reescrito como:

$$
\begin{aligned}
& \qquad y_{i t}=\bar{\beta}_{0}+\beta_{1} x_{1 i t}+\cdots+\beta_{n} x_{n i t}+v_{i t} \\
& \text { onde } v_{i t}=e_{i t}+\alpha_{i}
\end{aligned}
$$

O novo termo possui diversas propriedades, de acordo com Hill, Griffiths e Judge (1999):

$$
\begin{gathered}
E\left(v_{i t}\right)=0 \\
\operatorname{var}\left(v_{i t}\right)=\sigma_{e}^{2}+\sigma_{a}^{2} \\
\operatorname{cov}\left(v_{i t}, v_{i s}\right)=\sigma_{a}^{2}, \quad \text { para todo } t \neq s \\
\operatorname{cov}\left(v_{i t}, v_{j t}\right)=0, \quad \text { para todo } i \neq j
\end{gathered}
$$

As duas primeiras propriedades remetem ao erro homocedástico, isto é, média zero e variância constante dos erros. A terceira propriedade caracteriza a autocorrelação, quando os erros de um mesmo indivíduo, em pontos distintos do tempo, são correlacionados. Já a quarta propriedade é sobre a falta de correlação dos erros de indivíduos diferentes no mesmo período temporal.

Considerando que, neste modelo, há correlação entre os erros do mesmo indivíduo em tempos distintos (propriedade 3), a estimação por mínimos quadrados ordinários (MQO) não é a mais apropriada, sendo o método dos mínimos quadrados generalizados (MQG) a melhor opção.

Assim como no modelo de efeitos fixos, há características que auxiliam a escolha pelo modelo de efeitos aleatórios - quando $\alpha_{i}$ não for correlacionado com todas as variáveis explicativas, o modelo aleatório é o mais indicado.

\subsection{Escolha e especificação do modelo}

Tendo em mente os dois modelos de regres- 
são em painel (fixo e aleatório), e de forma a parametrizar a escolha do tipo de regressão a ser utilizada, foi aplicado o teste de Hausman. Esse teste tem como hipóteses:

\section{$H_{0}$ : não há correlação entre os erros $H_{A}$ : há correlação entre os erros}

Ou seja, a hipótese nula nos afirma que o melhor modelo, de acordo com os dados, é o de efeitos aleatórios, e a hipótese alternativa nos afirma que a regressão em painel com efeitos fixos é a melhor opção.

Para a aplicação do método, foi utilizada como variável dependente, a ser predita, o índice de produtividade dos magistrados (no caso em tela, dos Juizados Especiais), em sintonia com estudo anterior (Gomes, Guimaraes, \& Akutsu, 2016). Para entender e explicar o comportamento dessa variável, foram utilizadas variáveis identificadas na revisão de literatura e outras que ajudam a elucidar o fenômeno, conforme pode ser visto no quadro abaixo.

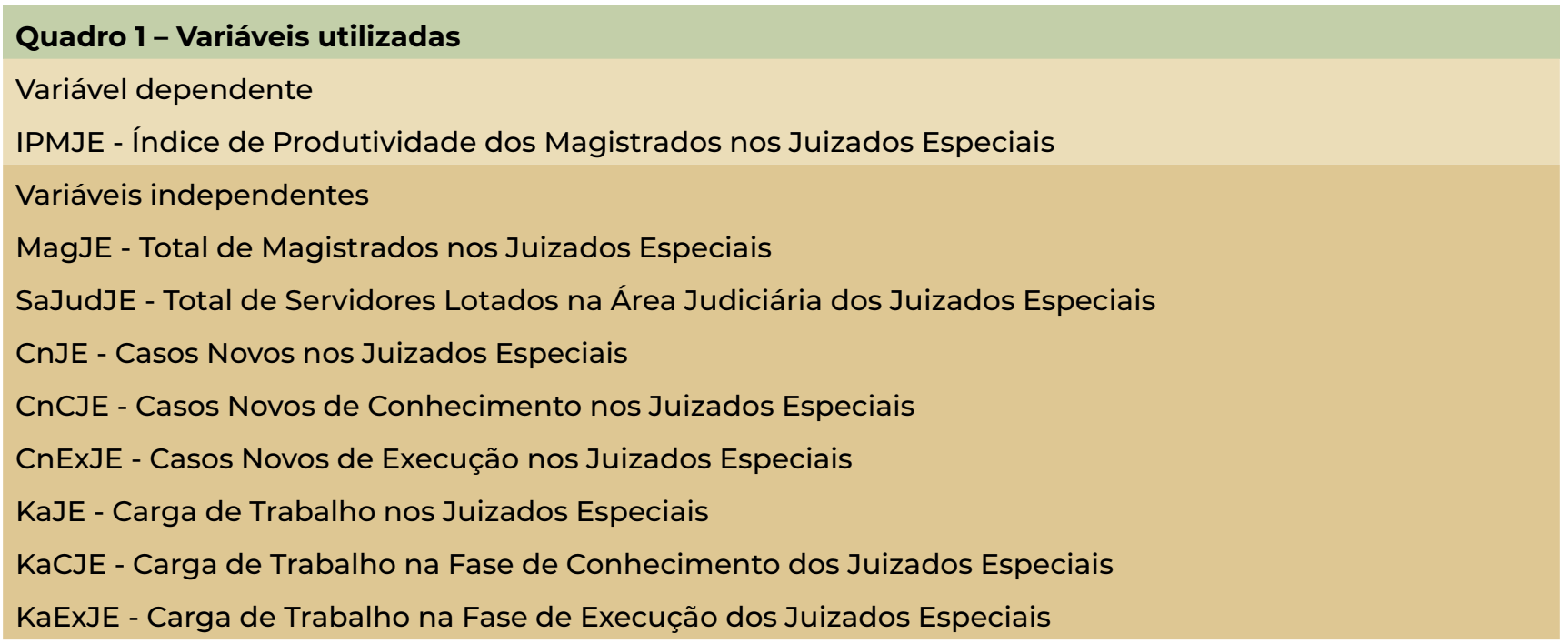

Fonte: os autores

A variável de interesse, o índice de produtividade dos magistrados nos Juizados Especiais (IPMJE), é a relação entre o total de processos baixados e o número de juízes que atuam nos Juizados Especiais. As variáveis explicativas são o número de magistrados que atuam nos Juizados Especiais (MagJE), o número de servidores lotados na área judiciária dos Juizados Especiais (SaJudJE), o total de casos novos ( $\mathrm{CnJE}$ ), que foi subdividido entre conhecimento ( $\mathrm{C} C \mathrm{CJE}$ ) e execução (CnExJE) e a carga de trabalho total (KaJE), também subdividida entre conheci- mento (KaCJE) e execução (KaExJE), com o objetivo de enriquecer a análise dos dados e oferecer alternativas para entendermos como funciona a produtividade nos Juizados Especiais.

Todas as variáveis utilizadas, com exceção das variáveis de carga de trabalho, não foram modificadas em relação ao relatório "Justiça em Números". Já a carga de trabaIho, para evitar problemas de colinearidade, foi alterada de forma a ter apenas o numerador, isto é, não mais contempla a carga de 
trabalho por magistrado, mas sim a carga de trabalho, em quantitativo de processos, que cada entidade tem em sua responsabilidade.

\section{RESULTADOS E DISCUSSÃO}

Com o intuito de explorar extensivamente as relações entre o índice de produtividade dos magistrados dos Juizados Especiais e as variáveis escolhidas como dependentes, foram rodados sete modelos distintos, a saber:

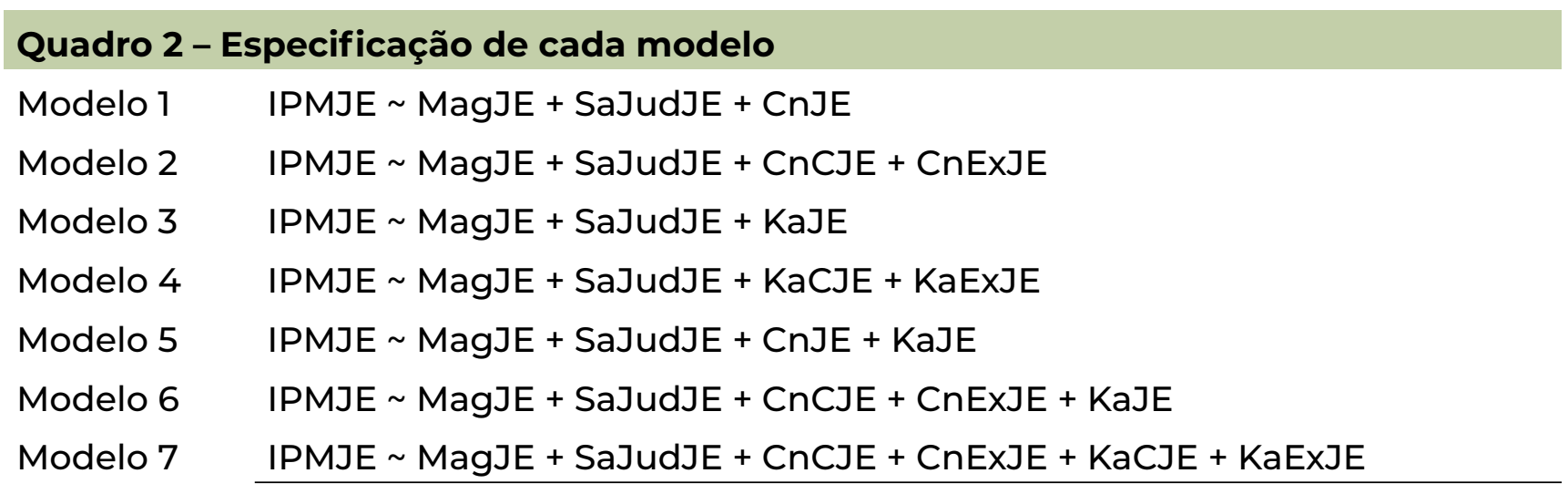

O primeiro modelo (Modelo 1) analisou a relação entre a produtividade e o número de magistrados, servidores da área judiciária e casos novos. O segundo modelo (Modelo 2) detalhou o anterior, utilizando os casos novos de conhecimento e execução. O terceiro modelo (Modelo 3) averiguou o comportamento entre o desempenho e os magistrados, servidores da área judiciária e a carga de trabalho. O quarto modelo (Modelo 4), mais uma vez, detalhou o anterior, diferenciando a carga de trabalho de conhecimento e execução. O Modelo 5 considerou além do número de magistrados e servidores da área judiciária, os casos novos e a carga de trabalho conjuntamente. O Modelo 6 parti- cularizou o anterior, avaliando as diferenças entre conhecimento e execução nos casos novos, enquanto o último modelo foi o mais detalhado do conjunto, considerando tanto os casos novos quanto a carga de trabalho de conhecimento e execução.

Em todos os modelos, o número de magistrados e de servidores da área judiciária foram mantidos, devido à importância de sua relação com o índice de produtividade. Já os casos novos e a carga de trabalho foram testados em diversas combinações e granularidades, como pode ser visto acima. Os resultados da regressão em painel aplicada aos dados dos Juizados Especiais estão resumidos na Tabela 6. 


\section{Tabela 6-Coeficientes das regressões em painel aplicadas nas variáveis de interesse, com os níveis de significância e $\mathbf{R}^{2}$ ajustado}

\begin{tabular}{|c|c|c|c|c|c|c|c|c|c|c|c|c|c|c|}
\hline Variável & Modelo 1 & & Modelo 2 & & Modelo 3 & & Modelo 4 & & Modelo 5 & & Modelo 6 & & Modelo 7 & \\
\hline MagJE & $-12,038$ & $* * *$ & $-12,22$ & $* * *$ & $-12,701$ & $* *$ & $-11,813$ & $* * *$ & $-12,256$ & $* * *$ & $-12,491$ & $* * *$ & $-12,53$ & $* * *$ \\
\hline SaJudJE & $-0,1754$ & & $-0,1597$ & & $-0,1054$ & & $-0,1029$ & & $-0,1932$ & & $-0,1742$ & & $-0,172$ & \\
\hline CnJE & 0,00875 & $* * *$ & & & & & & & 0,0075 & $* *$ & & & & \\
\hline CnCJE & & & 0,00863 & $* * *$ & & & & & & & 0,00735 & $* *$ & 0,00717 & $*$ \\
\hline CnExJE & & & 0,01017 & & & & & & & & 0,00899 & & 0,01018 & \\
\hline KaJE & & & & & 0,00194 & $*$ & & & 0,00063 & & 0,00066 & & & \\
\hline $\mathrm{KaCJE}$ & & & & & & & 0,00344 & $* * *$ & & & & & 0,00077 & \\
\hline KAEXJE & & & & & & & 0,00267 & & & & & & 0,00002 & \\
\hline $\begin{array}{l}R^{2} \\
\text { ajustado }\end{array}$ & 0,16737 & & 0,16381 & & 0 & & 0,15604 & & 0,17183 & & 0,17253 & & 0,17173 & \\
\hline
\end{tabular}

Fonte: os autores

Níveis de significância:

*** - 0,001 ** - 0,01 * - 0,05

Nota: O teste de Hausman indicou que o modelo de efeitos fixos seria o mais adequado nesse caso

O teste $\mathrm{F}$ do modelo de regressão em painel, que verifica a existência da regressão, foi significativo em todos os casos, indicando que, globalmente, todos os modelos são válidos. O teste de Hausman foi aplicado a todos os pares de modelos (fixo e aleatório) e mostrou que apenas o Modelo 3 seria mais adequadamente, de efeitos fixos. $O \mathrm{R}^{2}$ ajustado, que mede o ajuste do modelo e ao mesmo tempo, possibilita a comparação entre modelos com variáveis distintas, pode ser dito como fraco ou inexistente (Costa, 2012).

Em todos os modelos rodados, a variável do número de magistrados foi a única sempre significante ( $p$-valor $<0,01)$, com efeito negativo e com pouca variação (entre 11,78 e 12,53), indicando que, ao longo dos anos e entre todas as entidades (TJs), o aumento do número de magistrados tem como resultado a diminuição da produtividade média dos mesmos. Esse resultado de certo modo confirma e complementa estudo feito no âmbito de varas federais que apontou correlação negativa entre quantidade de juízes e produtividade (Gomes \& Freitas, 2017). 0 quantitativo de servidores da área judiciária segue o mesmo raciocínio, mas os resultados encontrados vão de encontro aos de outros artigos que analisaram a influência das equipes de apoio (Gomes, Guimaraes, \& Akutsu, 2016; El-Bialy, 2016), mas cumpre atentar que é difícil estabelecer inferências nesse ponto, uma vez que a variável não apresentou significância estatística.

Os modelos que utilizaram os casos novos mostraram que o efeito é significativo e positivo, ou seja, o crescimento do número de casos novos ao longo dos anos e entre as entidades, se traduz em aumento, ainda que pequeno, na produtividade, resultado que corrobora os achados de Dimitrova-grajzl et al. (2012). Ao analisarmos as fases de conhecimento e execução separadamente, ape- 
nas a fase de conhecimento apresentou-se significante e isso pode ser reflexo das diferenças entre esses ritos. A cada edição anual, o Relatório Justiça em Números tem destacado o impacto negativo gerado pela fase de execução nos dados de litigiosidade do Poder Judiciário brasileiro, que acumula alto volume processual e alta taxa de congestionamento (Brasil, 2017). Importante ressaltar que todos os TJs apresentam taxa de congestionamento na execução maior que no conhecimento, mas isso sinaliza um problema estrutural do judiciário brasileiro no que concerne à debilidade dos mecanismos de satisfação dos créditos e de cumprimento integral das sentenças.

A carga de trabalho apresentou o efeito similar aos casos novos (aumento correspondente na produtividade), mas mostrou-se significativa apenas no Modelo 3. A separação entre conhecimento e execução mostrou, no Modelo 4, que apenas a fase de conhecimento foi significante. O último modelo, que contemplou todas as variáveis em seus níveis mais desagregados, teve como variáveis significativas apenas os magistrados e os casos novos de conhecimento.

\section{CONSIDERAÇÕES FINAIS}

O presente estudo buscou analisar, sob a ótica da produção e da produtividade, o desempenho dos juizados especiais na Justiça Estadual brasileira. Tal reflexão é importante, uma vez que é relevante investigar se esse modelo de prestação jurisdicional tem sido eficaz no compromisso com a celeridade do processo, considerando que foi esse o princípio orientador da implantação dos juizados a partir da Lei n. 9.099 de 1995.

Primeiramente, há que se atentar para o aumento no volume de processos pendentes e de casos novos, 5,08\% e 3,07\% respecti- vamente no período analisado (2009-2016). Todavia, esse crescimento ainda não parece ter comprometido significativamente a velocidade de conclusão dos processos, uma vez que, pelo menos quando comparados à Justiça Comum, os juizados especiais ainda apresentam um crescimento de 2,86\% no número de processos baixados ao longo dos sete anos. Por ser um modelo de justiça marcado pela simplificação de procedimentos e pelo incentivo à conciliação entre as partes, cabe investigar porque essa fase conciliatória não tem sido tão efetiva quanto poderia ser. A relativa predominância de temas afetos a direito do consumidor também pode apontar para um funcionamento deficiente de instâncias administrativas e pré-processuais, como no caso dos Programas de Proteção e Defesa do Consumidor (PROCONs) estaduais.

Há que se ressaltar, contudo, uma limitação desta pesquisa no que tange à análise dos dados no âmbito da Justiça Estadual. Ainda que a separação de processos por meio do rito processual adotado seja de fácil operacionalização, a frequente existência de magistrados e servidores atuando simultaneamente na Justiça Comum e em juizados especiais pode embutir vieses cuja identificação, tratamento e controle vão além do escopo deste estudo. Em virtude da heterogeneidade das experiências de implantação dos juizados especiais por todo o país, sugere-se a realização de estudos comparados com vistas à identificação de especificidades que um modelo de caráter global, como o presente, não chega a captar. O Tribunal de Justiça do Distrito Federal, que é marcado por varas exclusivas de competência de juizado especial, pode servir para um estudo de caso relevante. Tais observações mostram que críticas ao processo de insti- 
tucionalização dos juizados, sobretudo no que tange à estruturação e uniformização do seu funcionamento nos judiciários locais (Cunha, 2008), permanecem atuais e que essa modalidade jurisdicional ainda está em construção, mesmo passados trinta anos de sua formalização no texto constitucional.

Os principais resultados encontrados no sentido de que o aumento de casos novos nos juizados especiais se traduz em aumento, ainda que pequeno, na produtividade, e também de que há indícios de correlação negativa entre quantidade de magistrados e produtividade, complementam estudo feito em varas federais (Gomes \& Freitas, 2017), o que amplia a moldura de entendimento dos fenômenos que ocorrem no multifacetado judiciário brasileiro e, por seu turno, incentiva olhares sobre outros ramos, como a Justiça do Trabalho, por exemplo. Um aprofundamento sobre a evolução da execução nos juizados, que não foi possível de ser captada na presente pesquisa, pode descortinar entendimentos importantes sobre o comportamento desse "gargalo" que dificulta o cumprimento integral das sentenças.

Espera-se que a pesquisa possa contribuir tanto para a reflexão acadêmica sobre desempenho judicial, ainda em sua infância no Brasil e no mundo, quanto para a análise dos profissionais diretamente encarregados da temática de gestão judiciária. Essa integração é oportuna e necessária para a efetiva implantação de mudanças e medidas corretivas no âmbito da administração da justiça.

\section{REFERÊNCIAS}

Andrade A., Joia L.A. (2012) Information Technology and the Efficiency of the Brazilian Judiciary System. In: Scholl H.J., Janssen M., Wimmer M.A., Moe C.E., Flak L.S. (eds) Electronic Government. EGOV 2012. Lecture Notes in Computer Science, vol 7443. Springer, Berlin, Heidelberg Baltagi B. H., Egger P., Pfaffermayr, M. (2012) A generalized spatial panel data model with random effects. $C E-$ Sifo Working Paper Series N. 3930.

Behn, R. D. (2003). Why measure performance? Different purposes require different measures. Public Administration Review, v. 63, n. 5, p. 586-606.

Brasil (2017). Conselho Nacional de Justiça (CNJ). Relatório Justiça em números 2017: Ano-base 2016. Brasília: CNJ, 2017 Disponível em: http://www.cnj.jus.br/programas-e-acoes/pj-justica-em-numeros. Acesso em: 07 nov. 2017

Castro, M. F., \& Guccio, C. (2014). Searching for the source of technical inefficiency in Italian judicial districts: an empirical investigation. European Journal of Law and Economics, 369-391.

Castro, M. F., \& Guccio, C. (2018). Measuring Potential Efficiency Gains from Mergers of Italian First Instance Courts through Nonparametric Model. Public Finance Review, 46(1), 83-116.

Chasin, A. (2012). A informalização da justiça e seu avesso: Uma análise das audiências de conciliação nos Juizados Especiais Cíveis de São Paulo. Dilemas - Revista de Estudos de Conflito e Controle Social, 5(2), 233-265. Recuperado de https://revistas.ufrj.br/index.php/dilemas/ article/view/7328

Choi, S. J., Gulati, M., \& Posner, E. A. (2013). How well do measures of judicial ability predict judicial performance? A case study using securities class actions. International Review of Law \& Economics, 33, 37-53.

Costa, G. C. (2012). Curso de Estatística Inferencial e Probabilidade. São Paulo: Atlas.

Cunha, L. G. (2008). Juizado Especial: criação, instalação, funcionamento e a democratização do acesso à Justiça. São Paulo: Saraiva.

Deyneli, F. (2012). Analysis of relationship between efficiency of justice services and salaries of judges with two-stage DEA method. European Journal of LaW and Economics, 34(3), 477-493. https://doi.org/10.1007/ s10657-011-9258-3

Dimitrova-Grajzl, V., Grajzl, P., Slavov, A., \& Zajc, K. (2015). Courts in a transition economy: Case disposition and 
the quantity-quality tradeoff in Bulgaria. Economic Systems, doi:10.1016/j.ecosys.2015.09.002

Dimitrova-grajzl, V., Grajzl, P., Sustersic, J., \& Zajc, K. (2012). Court output, judicial staffing, and the demand for court services: Evidence from Slovenian courts of first instance. International Review of Law \& Economics, 32(1), 19-29. https://doi.org/10.1016/j.irle.2011.12.006

El-Bialy, S. V. N. (2016). Identifying the determinants of aggregate judicial performance: taxpayers' money well spent? European Journal of Law and Economics, 283319.

Esposito, G., Lanau S., \& Pompe, S. (2014). Judicial System Reform in Italy-A Key to Growth. International Monetary Fund Working Paper, 14, 32.

Fabri, M. \& Langbroek (2000). The challenge for change for judicial systems: developing a public administration perspective. Amsterdam: IOS Press.

Falavigna, G., Ippoliti, R., Manello, A., \& Ramello, G. B. (2014). Judicial productivity, delay and efficiency: A Directional Distance Function (DDF) approach. European Journal of Operational Research, 240(2), 592-601.

Gomes, A. O. \& Freitas, M. E. (2017). Correlação entre demanda, quantidade de juízes e desempenho judicial em varas da Justiça Federal no Brasil. Revista Direito GV, São Paulo, 13 (2), 567-585.

Gomes, A. O., Guimaraes, T. A., \& Akutsu, L. (2016). The Relationship between Judicial Staff and Court Performance: Evidence from Brazilian State Courts. International Journal for Court Administration, 8(1).

Gomes, A. O. \& Guimarães, T. A (2013). Desempenho no Judiciário: conceituação, estado da arte e agenda de pesquisa. Revista de Administração Pública, Rio de Janeiro, 47 (2), p. 379-401.

Guerra, A., \& Tagliapietra, C. (2017). Does Judge Turnover Affect Judicial Performance? Evidence from Italian Court Records. Justice System Journal, 38(1), 52-77.

Hill, R. C., Griffiths, W. E. e Judge, G. G.. Econometria. São Paulo: Saraiva, 1999.

IPEA (2010). Estado, Instituições e Democracia: República. Livro 9, v. 1, Brasília, p. 131-174.

IPEA (2013). Diagnóstico sobre os juizados especiais cíveis. Brasília: IPEA. Disponível em: http://ipea.gov.br/agencia/images/stories/PDFs/relatoriopesquisa/181013_diagnstico_sobre_juizados.pdf.

Major, W. (2015). Data Envelopment Analysis as an Instrument For Measuring the Efficiency of Courts. Operations Research and Decisions, (4), 19-34. https://doi.org/10.5277/ ord150402

Mello, M. P. \& Meirelles, D. R. S. (2010). Juizados Especiais: entre a legalidade e a legitimidade - análise prospectiva dos juizados especiais da comarca de Niterói. Revista Direito GV, São Paulo, 6 (2), 371-398.

Nogueira, J. M. M., Oliveira, K. M. M. de, Vasconcelos, A. P. De, \& Oliveira, L. G. L. (2012). Estudo exploratório da eficiência dos Tribunais de Justiça estaduais brasileiros usando a Análise Envoltória de Dados. Revista de Administração Pública, 46(5), 1317-1340.

Nogueira, J. M. (2010). A gestão do poder judiciário: uma análise do sistema de mensuração de desempenho do judiciário brasileiro.109f. Dissertação (Mestrado em Administração Pública e Governo) - Fundação Getúlio Vargas, São Paulo. Disponível em: < http://bibliotecadigital. fgv.br/dspace/handle/10438/8218>, acesso em 20 abr 2017. Pekkanen, P., \& Niemi, P. (2013). Process performance improvement in justice organizations - Pitfalls of performance measurement. International Journal of Production Economics, 143(2), 605-611.

Peyrache, A., \& Zago, A. (2015). Large courts, small justice! The inefficiency and the optimal structure of the Italian justice sector. Omega, 64, 1-15.

Sadek, M. T. \& Oliveira, F. L. (2012). Estudos, pesquisas e dados em Justiça in Oliveira, F. L. (org). Justiça em Foco. Rio de janeiro: Editora FGV.

Santos, B. S. (2005). Os actos e os tempos dos juízes: contributos para construção de indicadores da distribuição processual nos juízos cíveis. Coimbra: Observatório Permanente da Justiça Portuguesa.

Santos, B. S (2007). Por uma revolução democrática da justiça. São Paulo: Cortez.

Vianna, L. W., Carvalho, M. A.; Melo, M. P. \& Burgos, M. B. (1999). A judicialização da política e das relações sociais no Brasil. Rio de Janeiro: Editora Revan.

Voigt, S. (2016). Determinants of judicial efficiency: a survey. European Journal of Law and Economics, 42(2), 183208.

Voigt, S., \& El-Bialy, N. (2016). Identifying the determinants of aggregate judicial performance: taxpayers' money well spent? European Journal of Law and Economics, 41, 283319. https://doi.org/10.1007/s10657-014-9474-8

Yeung, L. (2014). Measuring Efficiency of Courts: An Assessment of Brazilian Courts Productivity. In Emrouznejad, A. \& Cabanda, E. (Eds.). Managing Service Productivity Using Frontier Efficiency Methodologies and Multicriteria Decision Making for Improving Service Performance. New York: Springer.

Data de submissão: 18/09/2018

Data de aceite: 16/12/2019 